\title{
Chemical Changes Occurring During the Weathering of Two Coating-Grade Asphalts
}

\author{
Sidney H. Greenfeld
}

(June 29, 1960)

\begin{abstract}
The chemical changes that occurred during the weathering of two coating-grade asphalts in accelerated weathering machines and outdoors were studied. Asphaltenes and watersoluble and volatile degradation products were produced from the oils in the asphalt. The increase in asphaltenes during exposure is attributable to the formation of oxygenated groups in the oil components rather than to polymerization of the oils. Some of the sulfur and nitrogen compounds originally in the oil fractions underwent chemical changes that made them insoluble in n-pentane.

The asphalts lost weight during the exposure. Roughly two-thirds of the material lost, including sulfur- and nitrogen-containing molecules, became water-soluble degradation products. The other third became volatile degradation products, probably $\mathrm{CO}_{2}$ and $\mathrm{H}_{2} \mathrm{O}$. An intermediate degradation product was separated with the asphaltenes. This material could be extracted from the asphaltene fraction with ethanol.

The reported observations were made on asphalts exposed in accelerated weathering machines. Outdoor exposures of the same asphalts were of too short duration to produce significant trends, but the general results were in agreement with the accelerated exposures.
\end{abstract}

\section{Introduction}

In the refining of petroleum, the more volatile constituents are removed by distillation. Because the process is conducted in the absence of oxygen and at temperatures at which cracking does not occur, few changes in individual molecules take place. When the lubricating oils have been removed, a heavy viscous residuum, or "flux," remains in the still pot, from which coating-grade asphalt is made by blowing air through it at a high temperature. From the time the flux enters the blowing still to the time it finally fails on a roof as an industrial asphalt, it undergoes a number of physical and chemical changes. The physical changes are primarily outward symptoms of the chemical changes that have taken place. Although almost nothing is known of the individual molecules, and very little has been reported on their chemical nature, these changes have been described on numerous occasions as oxidation, dehydrogenation, carbonization, polymerization, and evaporation [1]. ${ }^{1}$

Several studies have been reported on the changes that occur during the blowing process. Kleinschmidt and Snoke [2] reported that the asphaltenes increased at the expense of the dark oils and resins. Goppel and Knotnerus [3] studied the conversion of maltenes into asphaltenes and established the actual formation of carbon-carbon and ester linkages as well as other oxidation and dehydrogenation reactions.

\footnotetext{
1 Figures in brackets indicate the literature references at the end of this paper.
}

Less detailed work has been done on the effects of weathering than on blowing. Abraham [1] has summarized the work of earlier investigators. He has stated that there is some volatilization of the lower molecular weight components of asphalt. He drew an analogy to the oxidation of lubricating oils and concluded that oxidation results in both an increase in oxygenated materials in the asphalt and an elimination of carbon dioxide and water. Thurston and Knowles [4] have confirmed this statement. Abraham also reported the formation of free carbon by the excessive dehydrogenation of asphalt during exposure. However, under normal exposure conditions no one has ever definitely established the formation of free carbon in asphalt. A large number of investigators have reported the formation of asphaltenes [5], material insoluble in low molecular weight aliphatic solvents, during exposure.

Kleinschmidt and Snoke [6], Abraham [5], Galloway [7], and others have described some of the changes that occurred in asphalt and its components during exposure to the elements of weather. In general, these authors observed that asphalt lost weight and the asphaltene fraction increased during: exposure, both at the expense of the components of the maltenes (the portion of asphalt soluble in n-pentane).

This paper carries the work one step further. In addition to following the weight losses and component changes during the exposure of two coatinggrade asphalts, it describes the changes in the elemental composition, unsaturation, and molecular weights of the various components. This information should prove valuable in developing an explanation of the mechanism of the weathering of asphalt. 


\section{Materials and Methods}

\subsection{Asphalts}

The two asphalts studied have been described as asphalts I and II in "The Effects of Mineral Additives on the Durability of Coating-Grade Roofing Asphalts" [8]. The characteristics of these asphalts are reported again in table 1 for convenience. They were commercially produced by blowing the fluxes described in table 2 .

TABLE 1. Characteristics of asphalts

\begin{tabular}{|c|c|c|}
\hline Characteristic & Asphalt I & Asphalt II \\
\hline $\begin{array}{l}\text { Softening point a } \\
\text { Penetration b at } 32^{\circ} \mathrm{F} \\
\text { Penetration at } 77^{\circ} \mathrm{F} \\
\text { Penetration at } 115^{\circ} \mathrm{F} \\
\text { Susceptibility } \mathrm{F}^{\mathrm{F}} \\
\text { Loss on heating } \mathrm{d} \\
\text { Pen after heating at } 77^{\circ} \mathrm{F} \\
\text { Specific gravity at } 77^{\circ} \mathrm{F} \\
\text { Durability e [9] } \\
\text { Component analysis }[12] \text { : } \\
\text { Asphaltenes. } \\
\text { Resins } \\
\text { Dark oils } \\
\text { White oils. }\end{array}$ & $\begin{array}{l}223 \\
10 \\
17 \\
30 \\
1.16 \\
0.22 \\
17 \\
1.015 \\
43 \\
41.8 \\
10.3 \\
18.2 \\
27.4\end{array}$ & $\begin{array}{l}224 \\
11 \\
17 \\
26 \\
0.87 \\
.03 \\
17 \\
0.999 \\
75 \\
39.1 \\
9.9 \\
23.3 \\
24.4\end{array}$ \\
\hline Recovery & 97.7 & 96.7 \\
\hline
\end{tabular}

a ASTM D36-26.

b ASTM D5-59T.

c $\mathrm{S}=\left(P_{115}-P_{32}\right) / P_{77}$

d ASTM D6-39T. of $22 \mathrm{hr}$ a day exposure to $51 \mathrm{~min}$ of light followed by $9 \mathrm{~min}$ of light and cold $\left(40^{\circ} \mathrm{F}\right)$ water spray. The $50 \%$ failure level was used. ASTM D 529-59T.

\subsection{Panel Preparation and Exposure}

The asphalt specimens were prepared by the hydraulic press method ${ }^{2}$ [9]. Twenty-nine specimens of asphalt I and 26 of asphalt II were exposed in an accelerated weathering machine [10] to a cycle consisting of $22 \mathrm{hr}$ of light from an enclosed carbon arc, followed by $1 \mathrm{hr}$ of soaking in distilled water and $1 \mathrm{hr}$ at ambient conditions daily, five days a week. The specimens were weighed approximately every $100 \mathrm{hr}$, just prior to a soaking period, for the first $1,200 \mathrm{hr}$. They were also weighed at approximately $1,500,1,700,2,200,2,500$, and $3,500 \mathrm{hr}$.

Eighteen specimens of each asphalt were exposed outdoors at an angle of $45^{\circ}$ facing due south. These specimens were weighed at 3 -month intervals during the first year and at 6-month intervals thereafter. After each weighing, a specimen of each asphalt was removed for analysis.

Three specimens of each asphalt were removed after the 200-, 400-, 600-, 900-, 1,200-, 1,700-, 2,500-, and 3,500-hr weighings for analysis. The other specimens, five of asphalt I and two of asphalt II, were used for special tests not included in this paper, but were included in the weight-loss determinations. Because of the periodic removal of specimens for analysis, each succeeding set of weighings was made on fewer specimens.

2 ASTM D1669-59T.

\subsection{Component Analysis}

The specimens removed from the accelerated weathering machines were each separated into components by the chromatographic method of Kleinschmidt [11] and the corresponding fractions combined to provide sufficient quantities of each component for chemical analysis. The reported component analyses are the averages of the three separations.

\subsection{Degradation Products}

The specimens were all soaked in distilled water for $1 \mathrm{hr}$ each cycle. All of the specimens of each asphalt were soaked in one glass container for 45 min and then for $15 \mathrm{~min}$ in a second one. At the exposure intervals reported in tables 3,4 , and 5 , the solutions of the accumulated water-soluble degradation products were removed, filtered, and evaporated to dryness in a vacuum evaporator at 120 to $135^{\circ} \mathrm{F}$. Because the water-soluble degradation products were extremely surface active, small portions of these materials were invariably lost through foaming in the evaporator. Fresh distilled water was used to refill the glass containers.

\subsection{Chemical Analyses}

The combined component fractions and the watersoluble degradation products were analyzed for molecular weight, unsaturation, carbon, hydrogen, sulfur, oxygen, and nitrogen. Because of the complex nature of the asphaltenes, some of the existing procedures had to be modified. The modifications to the chemical procedures have been reported [12] previously.

The molecular weights were determined by an ebullioscopic method developed by Matteson [13].

The unsaturation was determined in chloroform with Wij's solution. The addition reaction took place in the dark at $70^{\circ} \mathrm{F}$ [14]. The original procedure was designed for relatively low-molecularweight compounds. To accommodate it to asphalt systems, the volume of chloroform was increased from 10 to $20 \mathrm{ml}$, and the volume of Wij's solution decreased from 25 to $5 \mathrm{ml}$. The repeatability of this procedure was of the order of \pm 0.2 double bond per gram of sample. The procedure ignores unsaturation in aromatic rings; it is primarily for olefinic unsaturation. Experience has shown that certain oxygenated and sulfur compounds can lead to high values under some conditions.

\section{Results}

Table 2 contains the results of the component and chemical analyses of the coating-grade asphalts used in this study and of the fluxes from which they were blown. The results of the component and chemical analyses of asphalt I at various exposure times are presented in table 3 , those of asphalt II in table 4 . The chemical analyses of the water-soluble degradation products of both asphalts are presented in table 5. Tables 6 and 7 contain the results of the analyses of the asphalts after outdoor exposures. 
TABLE 2. Properties and chemical analyses of fluxes and asphalts

\begin{tabular}{|c|c|c|c|c|}
\hline \multirow{2}{*}{ Property } & \multicolumn{2}{|c|}{ Asphalt I } & \multicolumn{2}{|c|}{ Asphalt II } \\
\hline & Flux & Asphalt & Flux & Asphalt \\
\hline $\begin{array}{l}\text { Softening pt } \\
\text { Viscosity at } 210^{\circ} \mathrm{F} \text { F.S }\end{array}$ & 84 & 223 & 286 & 224 \\
\hline $\begin{array}{l}\text { Asphaltenes... } \\
\text { Resins } \\
\text { Dark oils } \\
\text { White oils } \\
\text { Recovery }\end{array}$ & $\begin{array}{l}\text { a } 13.2(1850) \\
\text { a } 16.8(1000) \\
\text { a } 29.8 \quad(670) \\
\text { a } 32.4 \quad(470) \\
92.2\end{array}$ & 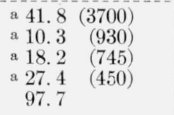 & $\begin{array}{l}\text { a } 13.2(2200) \\
\text { a } 16.5(1250) \\
\text { a } 37.6(1020) \\
\text { a } 29.0(950) \\
96.3\end{array}$ & $\begin{array}{rr}\text { a } 39.1 & (4400) \\
\text { a } 9.9 & (1100) \\
\text { a } 23.3 & (900) \\
\text { a } 24.4 & (500) \\
96.7 & \end{array}$ \\
\hline Chemical analyses & & & & \\
\hline $\begin{array}{l}\text { Carbon } \\
\text { Hydrogen } \\
\text { C/H (atomic ratio) } \\
\text { Oxygen } \\
\text { Sulfur } \\
\text { Nitrogen } \\
\quad \text { Total }\end{array}$ & $\begin{array}{r}84.64 \\
10.89 \\
0.65 \\
.70 \\
2.18 \\
1.11 \\
99.52\end{array}$ & $\begin{array}{r}83.89 \\
10.29 \\
0.69 \\
1.79 \\
2.27 \\
1.23 \\
99.47\end{array}$ & $\begin{array}{r}86.51 \\
10.71 \\
0.68 \\
.26 \\
1.15 \\
0.90 \\
99.53\end{array}$ & $\begin{array}{r}85.51 \\
10.29 \\
0.70 \\
1.27 \\
1.24 \\
0.69 \\
99.00\end{array}$ \\
\hline
\end{tabular}

a Numbers in parentheses are number average molecular weights.

TABLE 3. Effects of accelerated weathering on asphalt I

(22-1 cycle)

\begin{tabular}{|c|c|c|c|c|c|c|c|c|c|c|c|c|}
\hline $\begin{array}{l}\text { Component, } \\
\text { exposure }\end{array}$ & Percent a & Mol. wt. & Unsat. & Unsat. & $\begin{array}{l}\text { Refractive } \\
\text { index }\end{array}$ & Carbon & Hydrogen & $\mathrm{C} / \mathrm{H}$ & Oxygen & Sulfur & Nitrogen & Total \\
\hline \multicolumn{13}{|c|}{ ASPHALTENES } \\
\hline \begin{tabular}{r}
\multicolumn{1}{c}{$h r$} \\
0 \\
200 \\
400 \\
600 \\
900 \\
1,200 \\
1,700 \\
2.500 \\
3,500
\end{tabular} & $\begin{array}{l}41.8 \\
46.9 \\
48.5 \\
48.7 \\
48.7 \\
48.9 \\
48.7 \\
47.6 \\
47.0\end{array}$ & $\begin{array}{l}3700 \\
3000 \\
2700 \\
3050 \\
3020 \\
2300 \\
2250 \\
\end{array}$ & $\begin{array}{c}\text { meg } d . b . \mathrm{b} / g \\
1.65 \\
1.55 \\
1.61 \\
1.66 \\
1.65 \\
1.65 \\
1.71 \\
1.96 \\
1.86\end{array}$ & $\begin{array}{c}\text { d.b. }{ }^{\mathrm{b}} / \mathrm{mole}- \\
\text { cule } \\
6.11 \\
4.65 \\
4.50 \\
5.06 \\
\\
4.98 \\
3.94 \\
4.41 \\
\end{array}$ & - & $\begin{array}{c}\% \\
83.53 \\
81.60 \\
\end{array}$ & $\begin{array}{c}\% \\
8.58 \\
8.35 \\
\end{array}$ & $\begin{array}{c}0.818 \\
.821 \\
\end{array}$ & $\begin{array}{c}\% \\
2.98 \\
4.17 \\
4.65 \\
4.68\end{array}$ & $\begin{array}{l}\% \\
2.38 \\
2.77 \\
2.88 \\
3.01 \\
2.93 \\
2.99 \\
2.92 \\
2.90 \\
2.67\end{array}$ & 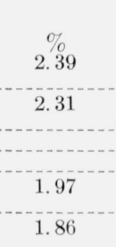 & $\begin{array}{c}\% \\
99.86 \\
99.79\end{array}$ \\
\hline
\end{tabular}

RESINS

\begin{tabular}{|c|c|c|c|c|c|c|c|c|c|c|c|c|}
\hline $\begin{array}{r}0 \\
200\end{array}$ & $\begin{array}{l}10.3 \\
11.4\end{array}$ & $\begin{array}{l}930 \\
965\end{array}$ & $\begin{array}{l}1.74 \\
1.51\end{array}$ & $\begin{array}{l}1.62 \\
1.46\end{array}$ & -- & 82.17 & 9.93 & 0.695 & $\begin{array}{l}\text { 2. } 72 \\
\text { 3. } 90\end{array}$ & $\begin{array}{l}3.32 \\
3.28\end{array}$ & 1. 34 & 99.48 \\
\hline 400 & 11. 4 & 990 & 1. 52 & 1. 50 & - & 80.77 & 10.29 & .660 & 4. 18 & 3. 22 & 1.15 & 99.61 \\
\hline 600 & 10.6 & 965 & 1.41 & 1. 39 & & & & ..... & 4. 70 & 3. 22 & & \\
\hline $\begin{array}{r}900 \\
\end{array}$ & $\begin{array}{l}9.6 \\
8.1\end{array}$ & 920 & 1. 44 & 26 & & & & $\cdots$ & -..... & 2. 96 & -- & \\
\hline $\begin{array}{l}1,200 \\
1,700\end{array}$ & $\begin{array}{l}8.1 \\
7.3\end{array}$ & 920 & $\begin{array}{l}1.37 \\
1.34\end{array}$ & 1.20 & & 79.70 & 10.63 & .630 & 5.11 & $\begin{array}{l}2.96 \\
2.88\end{array}$ & 0.75 & 99.07 \\
\hline 2,500 & 5. 6 & 950 & 1. 43 & 1. 36 & - n. & 79.41 & 10.53 & .633 & 6.18 & 2. 71 & - n & \\
\hline 3. 500 & 5.6 & $\cdots$ & 1.33 & 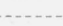 & - & 80.40 & 10.55 & .641 & 5. 95 & 2. 59 & .61 & 100.10 \\
\hline
\end{tabular}

\section{DARK OILS}

\begin{tabular}{|c|c|c|c|c|c|c|c|c|c|c|c|c|}
\hline 0 & 18. 2 & 745 & 1. 57 & 1. 17 & $\begin{array}{l}50^{\circ} \mathrm{C} \\
1.554\end{array}$ & 84.40 & 10.77 & 0.658 & 1.15 & 2. 65 & 0.57 & 99.54 \\
\hline 200 & 13.6 & 720 & 1. 58 & 1. 14 & 1.554 & & & & 1.25 & 2.45 & & \\
\hline 400 & 11.3 & 760 & 1. 50 & 1. 14 & 1. 548 & 85.11 & 10.33 & .692 & 1. 50 & 1. 99 & .48 & 99.41 \\
\hline 600 & 10.0 & 750 & 1. 50 & 1.12 & 1. 537 & & & $-\cdots$ & 1. 39 & 1. 80 & & \\
\hline $\begin{array}{r}900 \\
1.200\end{array}$ & $\begin{array}{l}8.9 \\
8.1\end{array}$ & 720 & $\begin{array}{l}\text { 1. } 51 \\
1.41\end{array}$ & 1.02 & $\begin{array}{l}1.535 \\
1.533\end{array}$ & & & & & $\begin{array}{l}\text { 1. } 67 \\
\text { 1. } 76\end{array}$ & & \\
\hline 1,700 & 7.0 & & 1. 34 & & 1.527 & 84.90 & 10.25 & .696 & 1.87 & 1. 40 & .49 & 98.91 \\
\hline 2,500 & 6.9 & 730 & 1. 26 & 0.92 & 1. 523 & 83.72 & 11. 02 & .640 & 2. 58 & 1. 43 & & \\
\hline 3,500 & 5.6 & & 1. 18 & & 1.516 & 83.82 & 10.93 & .642 & 2. 42 & 1.05 & .20 & 98.42 \\
\hline
\end{tabular}

\section{WHITE OILS}

\begin{tabular}{|c|c|c|c|c|c|c|c|c|c|c|c|c|}
\hline 0 & 27.4 & 450 & 0.84 & 0.38 & $\begin{array}{l}25^{\circ} \mathrm{C} \\
1.4982 \\
1.4969\end{array}$ & 85.77 & 12. 92 & 0.557 & 0.05 & 0.94 & 0.00 & 99.68 \\
\hline 200 & 24.5 & 520 & $\begin{array}{r}.64 \\
44\end{array}$ & .33 & $\begin{array}{l}1.4969 \\
1.4952\end{array}$ & & & & .16 & .58 & & \\
\hline 400 & 22.9 & 560 & .44 & .25 & 1.4952 & 85.90 & 12.67 & .570 & .05 & .44 & .42 & 99.48 \\
\hline 600 & 21.6 & 540 & .46 & .25 & 1. 4940 & & 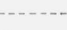 & . & .06 & .32 & & ..... \\
\hline $\begin{array}{r}900 \\
1,200\end{array}$ & $\begin{array}{l}20.3 \\
18.5\end{array}$ & 520 & $\begin{array}{l}.70 \\
.39\end{array}$ & .20 & $\begin{array}{l}\text { 1. } 4932 \\
\text { 1. } 49224\end{array}$ & & & & & $\begin{array}{r}.34 \\
.29\end{array}$ & & \\
\hline 1,700 & 17.9 & & .35 & & 1. 4912 & 86.28 & 13. 30 & .545 & .00 & .14 & .33 & 100.05 \\
\hline 2,500 & 17.8 & 530 & .36 & .19 & 1. 4892 & 85.71 & 12.95 & .557 & .24 & .20 & & \\
\hline 3,500 & 15.7 & & .26 & & 1. 4888 & 85.48 & 12.66 & .577 & .10 & .13 & .26 & 98.63 \\
\hline
\end{tabular}

a Percent of original asphalt, by weight.

b Double bonds. 
TABLI 4. Effects of accelerated weathering on asphalt II

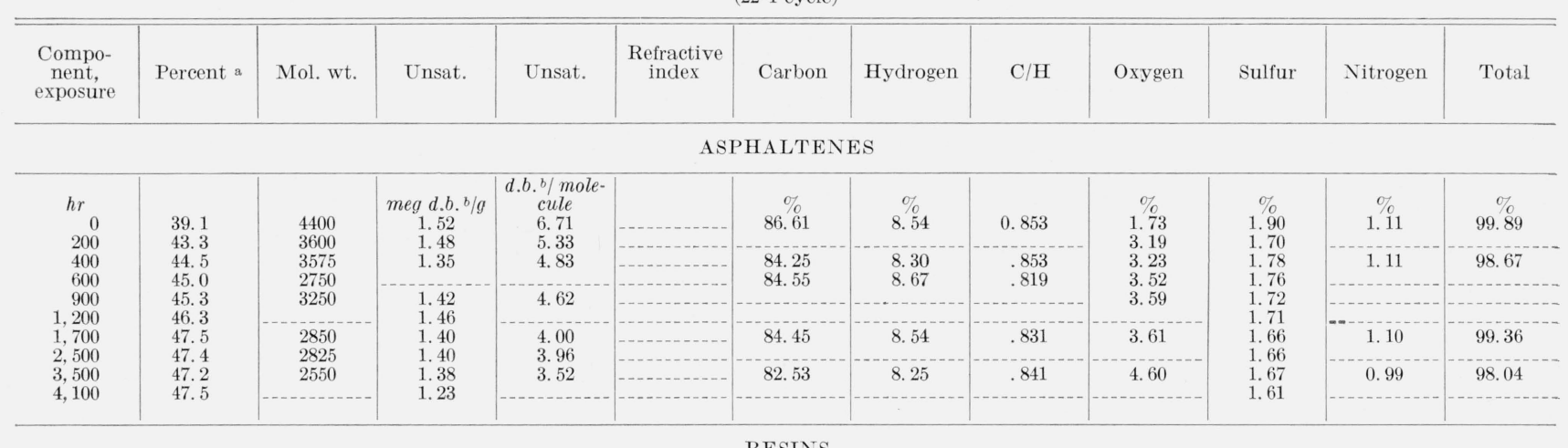

RESINS

\begin{tabular}{|c|c|c|c|c|c|c|c|c|c|c|c|c|}
\hline $\begin{array}{r}0 \\
200\end{array}$ & $\begin{array}{r}9.9 \\
10.9\end{array}$ & $\begin{array}{r}1100 \\
975\end{array}$ & $\begin{array}{l}\text { 1. } 25 \\
1.38\end{array}$ & $\begin{array}{l}\text { 1. } 37 \\
1.35\end{array}$ & & 84.85 & 10.38 & 0.687 & $\begin{array}{l}1.81 \\
2.65\end{array}$ & $\begin{array}{l}\text { 1. } 51 \\
1.47\end{array}$ & 1.01 & 99.56 \\
\hline 400 & 10.7 & 980 & 1. 24 & 1. 20 & -1 & 84.09 & 10.60 & .666 & 3. 00 & 1. 42 & 0.78 & 99.89 \\
\hline 600 & 10.6 & 1060 & 1. 20 & 1. 28 & -- & 83.64 & 10.91 & .644 & 3. 21 & 1.45 & & \\
\hline 900 & 10.0 & & 1.13 & & & & & & 3.36 & 1. 46 & & \\
\hline 1,200 & 9.0 & 1250 & 1.07 & 1. 33 & & & & & & 1. 43 & & \\
\hline 1,700 & 8.1 & 1260 & 1.07 & 1. 35 & $-\ldots$ & 83.38 & 10.93 & .641 & 3. 90 & 1. 41 & .58 & 100. 20 \\
\hline 2,500 & 8.1 & 1190 & 1. 05 & 1. 25 & - & & & & & 1.32 & & \\
\hline $\begin{array}{l}3,500 \\
4,100\end{array}$ & $\begin{array}{l}8.0 \\
7.13\end{array}$ & 1200 & $\begin{array}{r}0.98 \\
.80\end{array}$ & 1. 18 & - & 82.10 & 11.15 & .619 & 4. 64 & 1.07 & .48 & 99.44 \\
\hline
\end{tabular}

DARK OILS

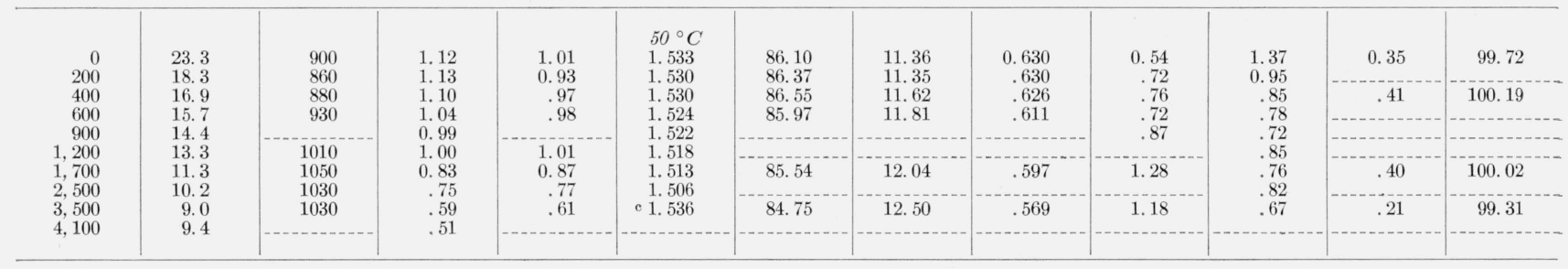

WHITE OILS

\begin{tabular}{|c|c|c|c|c|c|c|c|c|c|c|c|c|}
\hline $\begin{array}{r}0 \\
200\end{array}$ & $\begin{array}{l}24.4 \\
23.6\end{array}$ & $\begin{array}{l}500 \\
560\end{array}$ & $\begin{array}{r}0.41 \\
33\end{array}$ & 0. 21 & $\begin{array}{l}25{ }^{\circ} \mathrm{C} \\
1,4871 \\
1,4870\end{array}$ & 86.29 & 13. 31 & 0.544 & $\begin{array}{r}0.00 \\
03\end{array}$ & 0. 35 & 0.20 & 100.15 \\
\hline 400 & 23.0 & 560 & .29 & .17 & 1. 4868 & 86.15 & 13.39 & .541 & .06 & .14 & .33 & 100.07 \\
\hline 600 & 23.0 & 675 & .27 & .18 & 1. 4860 & 85. 94 & 13.80 & .523 & .12 & .15 & .00 & - \\
\hline 900 & 21.3 & 885 & .22 & .19 & 1. 4858 & & & & .18 & .19 & & \\
\hline 1,200 & 20.5 & 920 & .28 & .26 & 1. 4858 & & & & & .11 & & \\
\hline 1,700 & 19. 7 & $\begin{array}{l}920 \\
920\end{array}$ & .23 & $\begin{array}{r}.20 \\
19\end{array}$ & $\begin{array}{l}1.4852 \\
1.4834\end{array}$ & 85.78 & 13.53 & .532 & .24 & .08 & .30 & 99.93 \\
\hline 3,500 & 16.7 & 880 & .20 & .18 & 1. 4828 & 85.82 & 13.21 & .545 & .08 & .06 & .11 & 99.28 \\
\hline 4,100 & 17.1 & - & .17 & & 1.4820 & & & & & .09 & & \\
\hline
\end{tabular}

a Percent of original asphalt, by weight.

b Double bonds.

- Fuzzy. 
TABLE 5. Characteristics of the water-soluble degradation products formed during accelerated weathering (22-1 cycle)

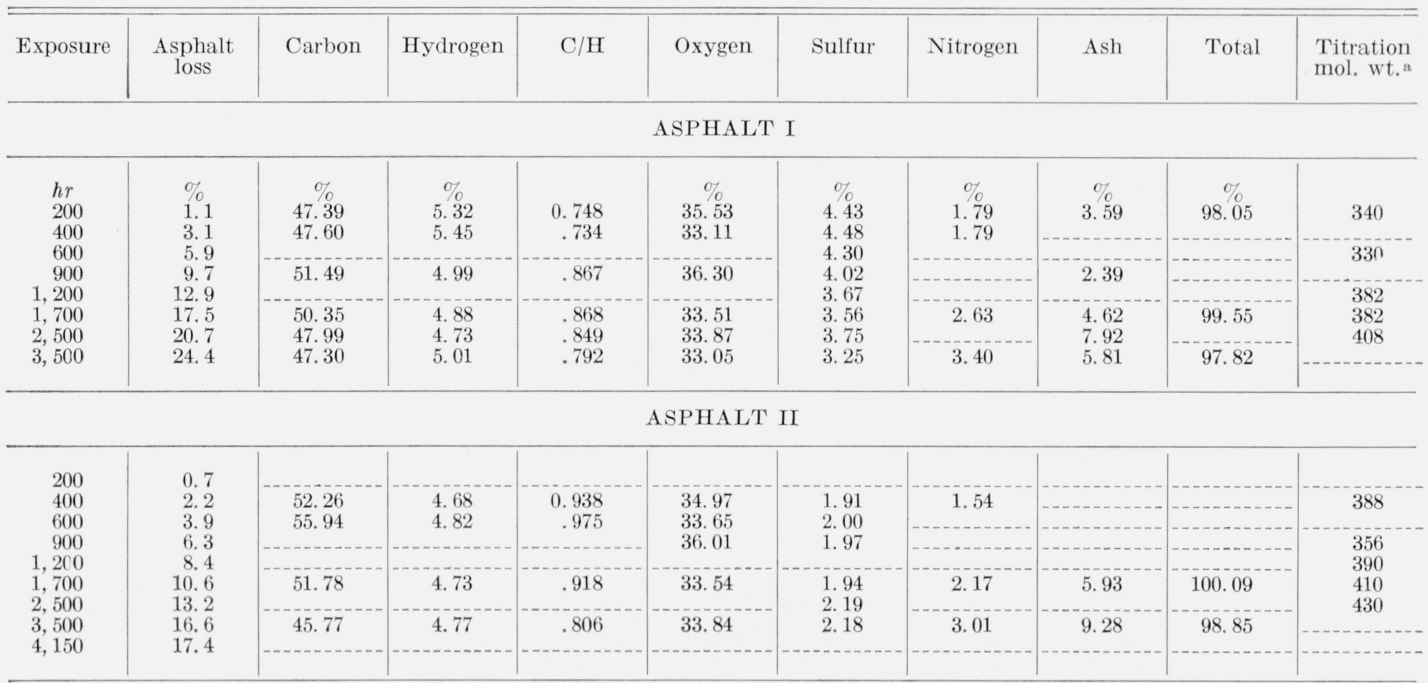

a Assuming two carboxyl groups per molecule.

TABLE 6. Effects of outdoor exposure on asphalt I

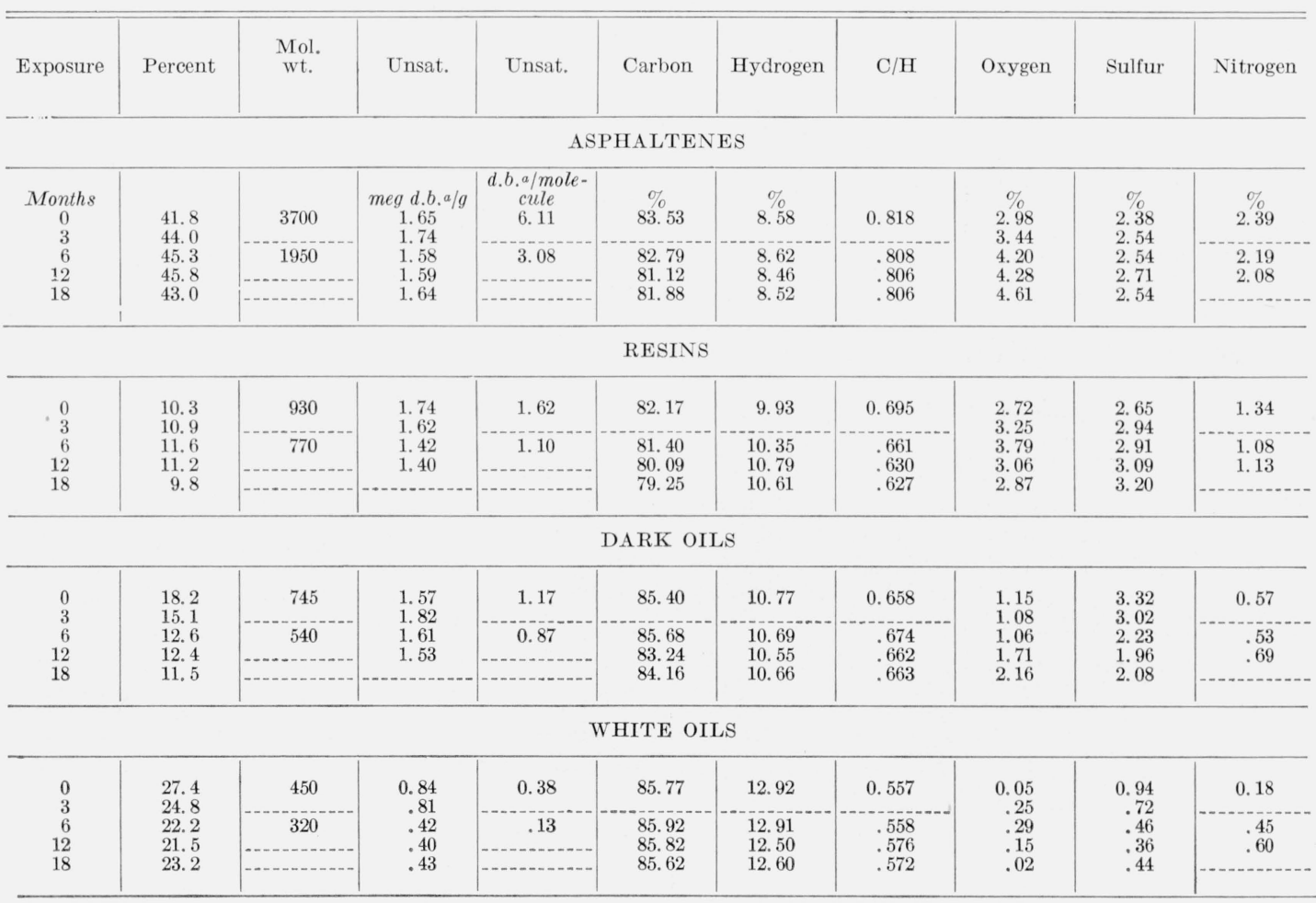

a Double bonds. 
TABLE 7. Effects of outdoor exposure on asphalt II

\begin{tabular}{|c|c|c|c|c|c|c|c|c|c|c|}
\hline Exposure & Percent & $\begin{array}{c}\text { Mol. } \\
\text { wt. }\end{array}$ & Unsat. & Unsat. & Carbon & Hydrogen & $\mathrm{C} / \mathrm{H}$ & Oxygen & Sulfur & Nitrogen \\
\hline \multicolumn{11}{|c|}{ ASPHALTENES } \\
\hline $\begin{array}{c}\text { Months } \\
0 \\
3 \\
6 \\
12 \\
18\end{array}$ & $\begin{array}{l}39.1 \\
40.3 \\
40.9 \\
42.2 \\
41.8\end{array}$ & $\begin{array}{r}4400 \\
4200 \\
2850 \\
\end{array}$ & $\begin{array}{c}\text { meg d.b.a/g } \\
1.52 \\
1.55 \\
1.71 \\
1.28 \\
1.38\end{array}$ & $\begin{array}{c}\text { d.b. a/mole- } \\
\text { cule } \\
6.71 \\
6.51 \\
4.88 \\
\end{array}$ & $\begin{array}{c}\% \\
86.61 \\
85.21 \\
84.48 \\
84.18\end{array}$ & $\begin{array}{c}\% \\
8.54 \\
8.42 \\
8.45 \\
8.38\end{array}$ & $\begin{array}{l}0.853 \\
.850 \\
.844 \\
.844\end{array}$ & $\begin{array}{c}\% \\
1.73 \\
2.26 \\
2.80 \\
2.52 \\
2.87\end{array}$ & $\begin{array}{r}\% \\
1.90 \\
1.98 \\
1.86 \\
1.78 \\
1.79\end{array}$ & $\begin{array}{c}\% \\
1.11 \\
1.20 \\
1.07 \\
-\end{array}$ \\
\hline \multicolumn{11}{|c|}{ RESINS } \\
\hline $\begin{array}{r}0 \\
3 \\
6 \\
12 \\
18\end{array}$ & $\begin{array}{r}9.9 \\
11.8 \\
11.0 \\
12.1 \\
9.2\end{array}$ & $\begin{array}{c}1100 \\
1180 \\
1160 \\
\end{array}$ & $\begin{array}{l}1.25 \\
1.40 \\
1.49 \\
1.22 \\
1.18\end{array}$ & $\begin{array}{l}1.37 \\
1.65 \\
1.73 \\
\end{array}$ & $\begin{array}{l}84.85 \\
84.00 \\
83.60 \\
82.12\end{array}$ & $\begin{array}{l}10.38 \\
10.44 \\
10.66 \\
10.28\end{array}$ & $\begin{array}{l}0.687 \\
.675 \\
.658 \\
.671\end{array}$ & $\begin{array}{l}1.81 \\
2.07 \\
2.52 \\
2.97 \\
4.12\end{array}$ & $\begin{array}{l}1.51 \\
1.68 \\
1.68 \\
1.52 \\
1.68\end{array}$ & $\begin{array}{l}1.01 \\
1.13 \\
0.76 \\
\end{array}$ \\
\hline \multicolumn{11}{|c|}{ DARK OILS } \\
\hline $\begin{array}{r}0 \\
3 \\
6 \\
12 \\
18\end{array}$ & $\begin{array}{l}23.3 \\
21.4 \\
20.5 \\
17.9 \\
14.6\end{array}$ & $\begin{array}{r}900 \\
1030 \\
940 \\
-\end{array}$ & $\begin{array}{l}1.12 \\
1.30 \\
1.41 \\
0.96 \\
1.09\end{array}$ & $\begin{array}{l}1.01 \\
1.34 \\
1.32 \\
\end{array}$ & $\begin{array}{l}86.10 \\
86.08 \\
86.26 \\
84.37\end{array}$ & $\begin{array}{l}11.36 \\
11.38 \\
11.00 \\
11.34\end{array}$ & $\begin{array}{l}0.630 \\
.636 \\
.658 \\
.625\end{array}$ & $\begin{array}{l}0.54 \\
.59 \\
1.07 \\
0.94 \\
1.55\end{array}$ & $\begin{array}{l}\text { 1. } 37 \\
\text { 1.26 } \\
1.16 \\
\text { 1. } 01 \\
1.26\end{array}$ & $\begin{array}{r}0.25 \\
.40 \\
.41 \\
.\end{array}$ \\
\hline \multicolumn{11}{|c|}{ WHITE OILS } \\
\hline $\begin{array}{r}0 \\
3 \\
6 \\
12 \\
18\end{array}$ & $\begin{array}{l}24.4 \\
23.7 \\
24.3 \\
20.5 \\
23.4\end{array}$ & $\begin{array}{r}500 \\
940 \\
800 \\
\end{array}$ & $\begin{array}{r}0.41 \\
.40 \\
.39 \\
.21 \\
.23\end{array}$ & $\begin{array}{r}0.21 \\
.38 \\
.32 \\
\\
\end{array}$ & $\begin{array}{l}86.29 \\
85.33 \\
84.33 \\
84.37\end{array}$ & $\begin{array}{l}13.31 \\
13.37 \\
12.79 \\
12.11\end{array}$ & $\begin{array}{l}0.544 \\
.536 \\
.553 \\
.584\end{array}$ & $\begin{array}{r}0.00 \\
.09 \\
.21 \\
.50 \\
.64\end{array}$ & $\begin{array}{r}0.35 \\
.29 \\
.25 \\
.12 \\
.11\end{array}$ & $\begin{array}{r}0.20 \\
.56 \\
.49 \\
\end{array}$ \\
\hline
\end{tabular}

a Double bonds.

Figures 1 and 2 are graphical presentations of the component changes during exposure.

Graphical presentations of material balances based on the elementary analyses of the asphalts and their water-soluble degradation products appear later in this paper as figures 3 to 8 , inclusive.

\section{Discussion of Results}

\subsection{General}

The origin of petroleum and the changes that occur during the ultimate conversion of petroleum and petroleum products to carbon dioxide and water are understood only vaguely. Some of the ehanges that

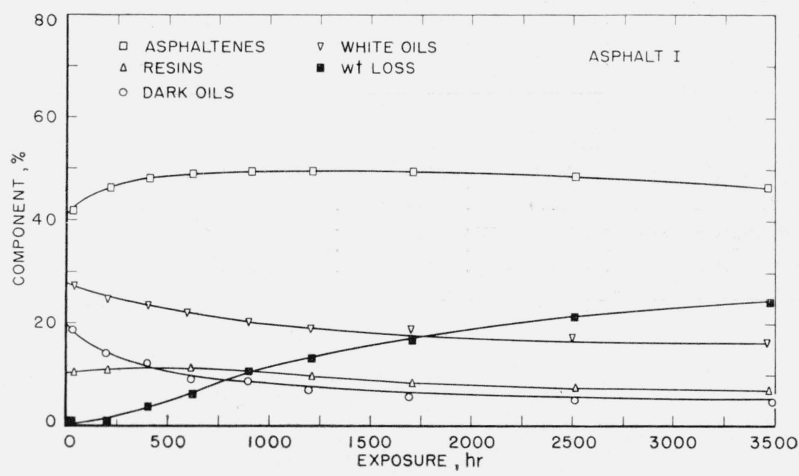

Figure 1. Change in components in asphalt I during exposure to accelerated weathering $22-1$ cycle.

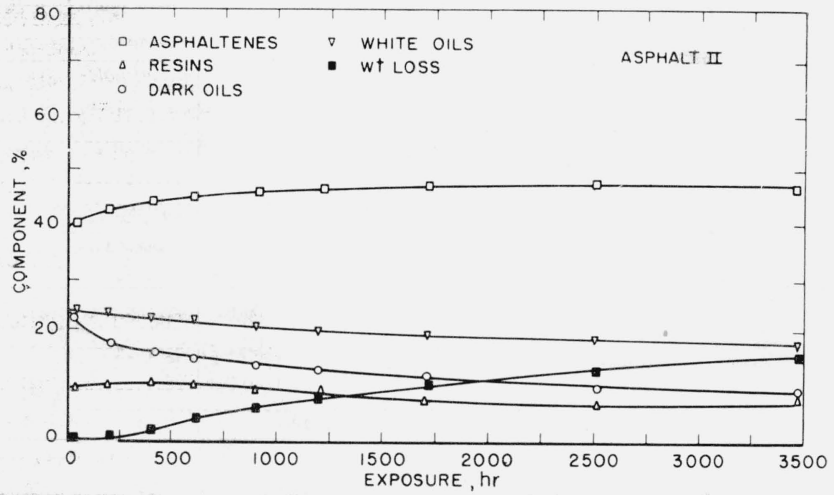

FIgURE 2. Change in components in aspha!t II during exposure to accelerated weathering $22-1$ cycle.

occur during the conversion of the organic source materials to crude petroleum have been studied by numerous investigators [16], and several hypotheses of the conversion exist. Considerably more work has been done on the combustion of petroleum fuels and oxidation of lubricating oils.

The chemical constituents of the lighter fractions of petroleum have been studied more zealously than those in asphalt, and considerable information has been accumulated on their compositions and properties. Less is known of the molecular species in the higher-boiling fractions; almost nothing is known of the individual molecules in asphalt and very little has been reported on their chemical nature. 


\section{Limitations of Analyses}

Except where indicated, the chemical analyses are averages of duplicate determinations. Two of these determinations, molecular weight and unsaturation, are somewhat controversial. The ebullioscopic method for determining molecular weights yields number-average molecular weights. These are weighted in favor of the lower-molecular-weight components in the sample. In addition, especially in the asphaltene fraction, it is generally recognized that aggregation of molecules exists to varying degrees in different environments and that particle, rather than molecular, weights are determined. In the limiting case, the particle and molecular weight are the same. Because the ebullioscopic procedure gives among the lowest values for molecular weights of asphaltenes, it is believed that these approach the true molecular weight values. However, although the molecular weights are of considerable interest, the changes that occur during exposure are of primary concern in this study.

Unsaturation determinations are occasionally higher than the true unsaturation because of the substitution of the iodine in organic molecules as well as its addition to double bonds. High values can also result from the presence of certain types of oxygen and sulfur linkages. However, while the true values are of importance, the changes in unsaturation are of primary interest in this study.

\subsection{Asphalt Flux}

The average molecular weight of flux I was 880 , and that of flux II was 1150 (table 2). In separating flux I into its components, a relatively large amount of material could not be removed from the fuller's earth column $(7.8 \%)$. This material probably was similar to, but more polar than, the resins. Flux II had significantly more dark oils and less white oils than flux I. Flux I contained more sulfur and oxygen than flux II.

During the blowing process, the fluxes had been oxidized at about $475{ }^{\circ} \mathrm{F}$ in a commercial blowing still. At a softening point of approximately $225^{\circ} \mathrm{F}$, the molecular weights of both asphalts had approximately doubled to 1970 and 2230 , respectively. The asphaltenes had increased, primarily at the expense of the resins and dark oils, both in quantity and molecular weight. The white-oil fraction of asphalt II was the only other portion that had changed significantly in molecular weight, having decreased almost 50 percent.

During the blowing process there was a 1 percent increase in the oxygen content of the asphalts, but no other significant elemental changes occurred. Thus, in summary, the blowing process oxidized the asphalt and increased its average molecular weight. It produced n-pentane-insoluble material of high molecular welght at the expense of some portions of the n-pentane-soluble fraction of the asphalt.

\subsection{Component Changes During Exposure}

When the two asphalts were exposed to light, heat, and water in an accelerated weathering machine in the laboratory, further changes took place. Because many of the changes are complex and tend to counterbalance other changes, the asphalts were separated into simpler groups, and the chemical changes occurring in each group were followed.

As seen in figures 1 and 2 , the asphalts lost weight during the entire course of the exposure. ${ }^{3}$ This weight loss amounted to 24.4 percent for asphalt I and 16.6 percent for asphalt II during the $3,500 \mathrm{hr}$ of exposure reported. The rate of loss was most rapid during the period between 400 and $600 \mathrm{hr}$ and then slowly tapered off.

Asphalt I failed by the conventional crack-failure criterion (50\% failure level) [8] at 1,500 hr; asphalt II did not fail until $4,150 \mathrm{hr}$ in the $22-1$ cycle. There was no indication of any sudden or unusual changes at the failure point.

Changes in components such as those shown in figures 1 and 2 have been reported previously [6] and will be discussed only briefly. All the analyses are based on the original weight of asphalt.

The asphaltenes increased rather rapidly at first and remained nearly constant in quantity during the last $3,000 \mathrm{hr}$ of exposure.

The resins increased during the first $400 \mathrm{hr}$ and then slowly decreased.

The dark oils decreased rather rapidly at first and more slowly during the last 2,000 hr.

The white oils followed a curve similar to the dark oils, but the initial decrease was small ər.

In summing up the changes in components, the asphaltenes increased at the expense of the oils during the early part of the exposure. The asphalt lost weight during the entire exposure at the expense of the oils and resins.

\subsection{Molecular-Weight Changes}

The molecular weight of each of the asphalts, which had increased during the blowing operation, began to decrease on exposure to the forces of degradation - light, heat, and water. In asphalt I, the molecular weight of the asphaltenes had increased during blowing from 1850 to 3700 ; it decreased to 2250 (table 3) during $3,500 \mathrm{hr}$ of exposure to the 22-1 cycle. Similarly, in asphalt II, the molecular weight of the asphaltenes had increased from 2200 to 4400 during blowing and decreased to 2550 (table 4) during $3,500 \mathrm{hr}$ of exposure. Although the molecular weight decreased appreciably, the quantity of asphaltenes increased during exposure. The newly formed asphaltenes are insoluble in n-pentane, apparently because of their polarity rather than their size.

In asphalt I, the molecular weight of each of the pentane-soluble fractions did not change appreciably during the blowing operation and changed little during exposure to the 22-1 cycle. In asphalt II the molecular weight of the white oils was almost halved during blowing, but increased progressively during exposure to the 22-1 cycle. The average

${ }^{3}$ Because the first weighings are reported at $200 \mathrm{hr}$ an initial gain in weight is not apparent from these data. 
molecular weights of the resins and dark oils decreased slightly during blowing and continued to decrease during the early periods of exposure, but soon increased to their values in the flux. Thus, during exposure, the molecules in both asphalts seemed to have returned to the size they were before the high-temperature oxidation process. The highermolecular-weight molecules possibly were the most reactive during blowing and the early stages of weathering. In the later stages of weathering the lower-molecular-weight molecules reacted. The net effect was to leave the middle-range-molecularweight molecules in the oils. Another possible explanation of these molecular-weight changes in the components of asphalt II might be in the formation of smaller molecules through the fragmentation of large molecules during blowing. These low-molecular-weight molecules could readily diffuse to the surface and be oxidized and removed during weathering. The net effect would be to lower the average molecular weights of the maltene fractions during blowing and increase these averages during weathering.

\subsection{Chemical Changes}

The chemical changes that took place during exposure may be stated as follows:

The unsaturation decreased during exposure as the asphalts were oxidized (table 8). Under the assumption that one oxygen molecule reacted at each double bond, it was found that the decrease in unsaturation was equivalent to the oxygen reacted with and retained in asphalt $I$, but only equivalent to one-half that in asphalt II. Apparently either unsaturation is being created during weathering in some of the molecules that remain in the asphalt, or some oxygen reacts at other positions than at the unsaturation. Both types of reactions probably occur because many oxidized molecules leave the asphalt as water-soluble and volatile degradation products. The formation of these products resulted in weight losses, which amounted to 24.4 and 16.6 percent for asphalts I and II, respectively, and will be discussed later. If oxygenated molecules interfered with the determination, then increased oxygen content of asphalt II may account for these high unsaturation values at $3,500 \mathrm{hr}$ of exposure.

In asphalt I, the carbon-hydrogen ratios of the components remained relatively unchanged during exposure as did their molecular weights. In combination with the relatively small melting range observed during specimen preparation, these facts tend to indicate a uniformity of molecular species. The decrease in refractive indices of the oil fractions of asphalt I during exposure (table 3) may then be attributed to a decrease in branching and a loss of double bonds [16]. In asphalt II, however, the carbon-hydrogen ratios tended to decrease (table 4) for all but the white oils (which are already very close to paraffinic in nature), indicating that the material remaining behind was more paraffinic than that being removed. The refractive-index decrease was somewhat less than in asphalt I, because the materials remaining in each component of the asphalt as degradation progressed were of increasingly higher molecular weight [16].

TABLE 8. Changes in oxygen and unsaturation of asphalts during $3,500 \mathrm{hr}$ of exposure

\begin{tabular}{|c|c|c|c|c|c|c|c|c|}
\hline \multirow{2}{*}{ Component } & \multirow{2}{*}{ Exposure } & \multirow{2}{*}{ Percent a } & \multicolumn{3}{|c|}{ Oxygen } & \multicolumn{3}{|c|}{ Unsaturation } \\
\hline & & & Percent & Weight b & Change & meq d.b.c/g & meq d.b.b, e & Change, d.b. ${ }^{\circ}$ \\
\hline
\end{tabular}

ASPHALT I

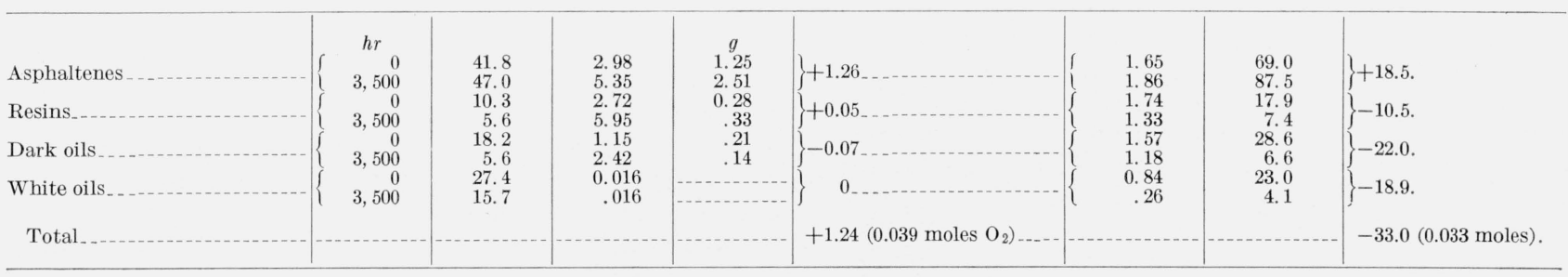

ASPHALT II

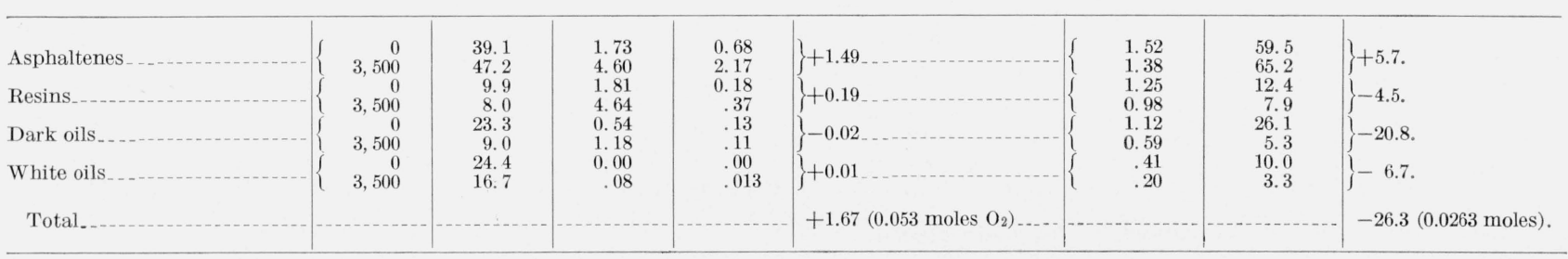

a Percent of original asphalt, by weight.

b Based on $100 \mathrm{~g}$ of asphalt.

c Milliequivalents of double bonds. 
The sulfur and nitrogen contents of both asphalts decreased progressively during exposure; both nitrogen and sulfur were present in some of the molecules that became water soluble. Apparently, however, the reaction that made the molecules water soluble did not take place at the sulfur or nitrogen bonds [17], for no oxidized forms of sulfur or nitrogen were found by chemical tests in the degradation products. ${ }^{4}$

Some of the sulfur-containing compounds reacted to form asphaltenes during the early stages of exposure. In asphalt I this reaction actually increased the concentration of sulfur in the asphaltenes, while in asphalt II the concentration remained the same. In both cases, a greater proportion of the sulfur in the asphalt appeared in the asphaltenes after exposure.

In asphalt I the nitrogen compounds seemed to be removed from the resins and dark oils, while in asphalt II only the resins lost nitrogen compounds. The materials that reacted to produce asphaltenes must have had about the same nitrogen content as the original asphaltenes because the nitrogen content of the asphaltenes remained almost constant during the first $400 \mathrm{hr}$ of exposure.

Water-soluble and volatile degradation products were formed during the exposure of the asphalts. Only the former were collected for analysis. The magnitude and probable composition of the latter will be discussed later. The water solubles (table 5) were highly oxidized, acidic materials containing appreciable nitrogen and sulfur [17]. Although, superficially, these products were similar during the entire exposure period, there were many differences present in the products collected during the various exposure intervals. The nitrogen content of the degradation products of asphalt I increased and the sulfur content decreased progressively as degradation proceeded. In the products of asphalt II, both nitrogen and sulfur increased.

The ash content of the water-soluble degradation products reported in table 6 was composed primarily of contaminating materials introduced by the reaction of the degradation products with the aluminumalloy specimen backings and supports and atmospheric contamination.

During the exposure period it was observed that a colored film formed on the surface of the asphalts. This film was composed of partially oxidized components of the asphalt. It was insoluble in npentane and remained with the asphaltenes during the separation process. While the amount of material in this film varied somewhat during exposure, it averaged about 4 percent of the weight of the original asphalt in asphalt $\mathrm{I}$, and 2 percent in asphalt II. It was extracted with hot ethanol from some of the asphaltenes of both asphalts. Some typical analyses of this material from asphalt I are presented in table 9 .

\footnotetext{
4 Stewart [18] suggested that an absorption band at about $97 \mu$ in asphalt components and their degradation products might represent a sulfoxide linkage; Beitchnents and their degradation products might represent a
man suggests it could also represent a C-O linkage [19].
}

TABLE 9. Ethanol extract of asphaltenes from asphalt $I$ at various exposure periods

\begin{tabular}{c|c|c|c|c|c|c|c}
\hline \hline $\begin{array}{c}\text { Exposure } \\
\text { time }\end{array}$ & $\begin{array}{c}\text { Percent of } \\
\text { original } \\
\text { asphalt }\end{array}$ & Carbon & $\begin{array}{c}\text { Hydro- } \\
\text { gen }\end{array}$ & C/H & Oxygen & $\begin{array}{c}\text { Nitro- } \\
\text { gen }\end{array}$ & Sulfur a \\
\cline { 1 - 2 } & & $\%$ & $\%$ & & & & \\
0 & 2.80 & 79.49 & 9.68 & 0.69 & 4.80 & 1.45 & 4.58 \\
1,700 & 4.87 & 73.95 & 9.32 & .67 & 11.15 & 0.77 & 4.81 \\
3,500 & 3.52 & 73.20 & 9.26 & .66 & b 11.65 & .78 & 5.11 \\
\hline
\end{tabular}

a By difference because of insufficient sample.

b Single determination.

Insufficient material was obtained from asphalt II for any complete analyses, but the oxygen content was determined at $400,1,200$, and $3,500 \mathrm{hr}$ to be $10.7,13.0$, and 14.2 percent, respectively. The nitrogen content was determined to be 0.60 percent at both 1,200 and $3,500 \mathrm{hr}$.

The ethanol extract is apparently an intermediate degradation product. It has been oxidized sufficiently to make it insoluble in n-pentane, but not enough to make it water soluble.

\subsection{Quantitative Considerations}

The above qualitative discussion of the changes that occurred in the two asphalts has shed some light on what transpires during exposure, but for a better understanding, the data must be examined quantitatively.

All of the complete elemental analyses accounted for between 98 and 100 percent of the material being analyzed, introducing a maximum of 2 percent uncertainty in any particular analysis. This difference was apportioned to each element in proportion to its concentration. In the component analyses there was usually about 2 to 3 percent of material that remained on the fuller's earth and was not included in the material that was collected for analysis. Subsequent work showed that this normally unrecovered material was of the same molecular weight as the resins and was similar to the resins in many other respects. As an approximation, it will be included in the following discussion as additional resins.

Thurston and Knowles [4] reported that for each mole of oxygen absorbed by an asphalt during exposure to ultraviolet light, an additional mole of oxygen went into $\mathrm{CO}_{2}$ and $\mathrm{H}_{2} \mathrm{O}$ formation. These authors reported no other volatile products. Therefore, all losses of volatile materials in the following discussion will be considered as $\mathrm{CO}_{2}$ and $\mathrm{H}_{2} \mathrm{O}$. Logically, then, all of the sulfur losses must have gone into tha nonvolatile, water-soluble degradation products, offering a convenient tracer for determining the amount of these products that has been formed. All of the carbon and hydrogen not in the watersoluble degradation products or the remaining asphalt must have gone into volatile degradation products. Because nitrogen can be introduced into the exposed asphalt by direct reaction of some of its oxides always 


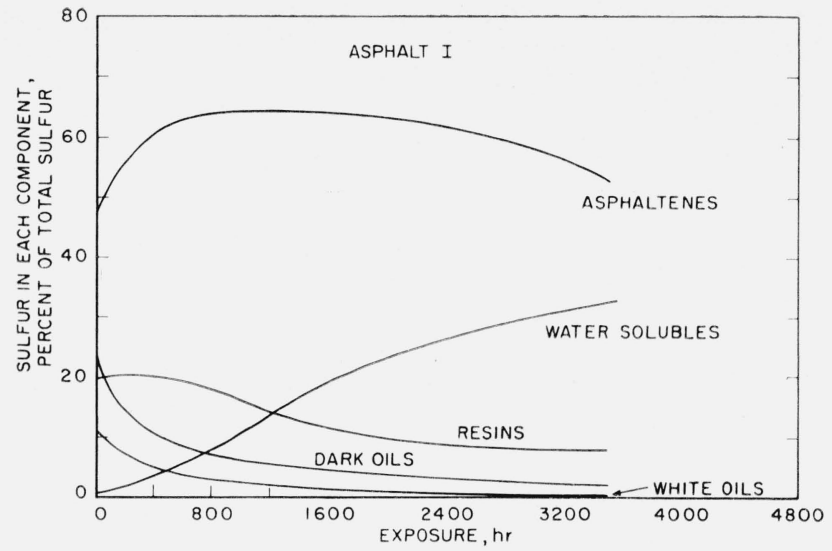

Figure 3. Sulfur distribution in asphalt I during exposure to accelerated weathering.

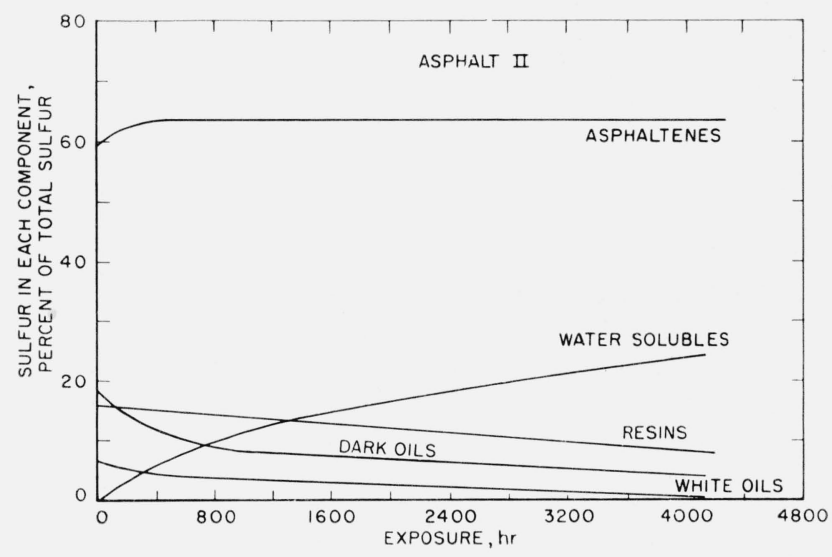

Figure 4. Sulfur distribution in asphalt II during exposure to accelerated weathering.

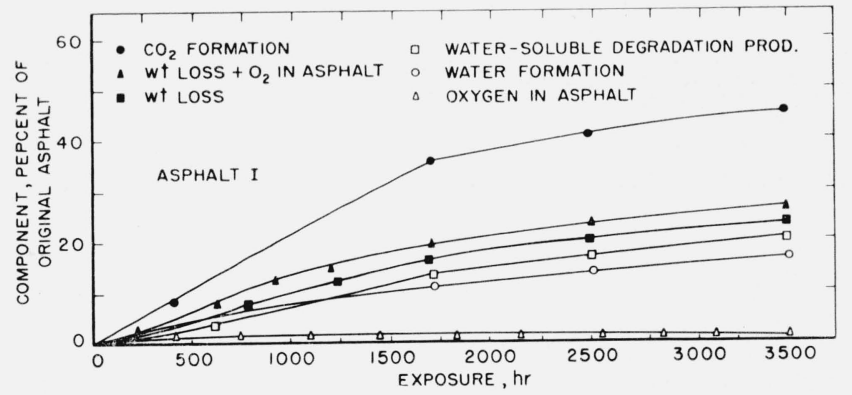

Figure 5. Oxygen distribution in asphalt I during exposure to accelerated weathering.

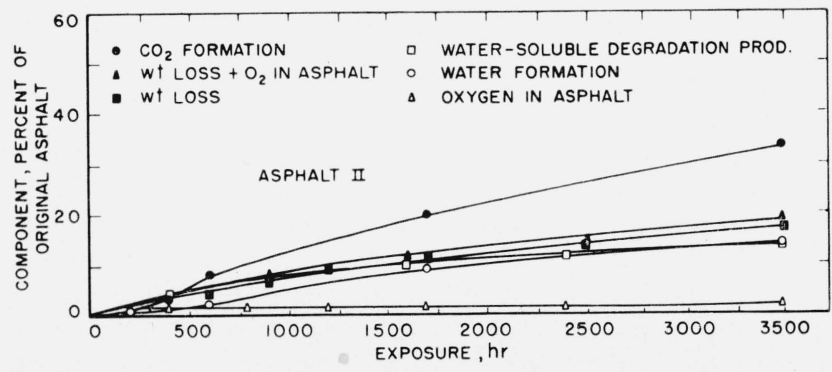

FIGURE 6. Oxygen distribution in asphalt II during exposure to accelerated weathering. present in the atmosphere at the unsaturation in the asphalt [19], it will be considered separately.

The sulfur distributions in the asphalts and watersoluble degradation products are shown in figures 3 and 4 . These curves closely parallel those of the changes in the components themselves. The conversion of compounds containing sulfur into asphaltenes during the period in which the asphaltenes were increasing is readily apparent as is the gradual progressive transfer of sulfur-containing materials from the maltene fractions to the water-soluble degradation products.

Figures 5 and 6 show the oxygen distributions for the two exposed asphalts and their degradation products. All of the data are expressed as percentages of the original asphalt in order to have a common basis for comparison. A number of very interesting observations may be made from these curves. Both asphalts increased continuously in oxygen content despite the fact that they were losing weight. At $3,500 \mathrm{hr}$, each had picked up just under 2 percent of oxygen. This oxygen "absorption" must be added to the actual weight loss to determine the net loss of each asphalt. The curves representing these figures are shown in figures 5 and 6 , also.

The curves labeled "water-soluble degradation products" were calculated from the quantity of sulfur lost from the asphalt and the percentage of sulfur found in the water-soluble degradation products. These curves are always lower than the weight-loss curves.

The carbon and hydrogen lost from the asphalt and not present in the nonvolatile degradation products was assumed to have gone into the volatile products as $\mathrm{CO}_{2}$ and $\mathrm{H}_{2} \mathrm{O}$. Each hydrogen molecule picked up roughly eight times its weight of oxygen; and each carbon atom, two and two-thirds times its weight. Thus, very large quantities of $\mathrm{CO}_{2}$ and $\mathrm{H}_{2} \mathrm{O}$ were formed, as indicated in figures 5 and 6 . While the data during the early part of the exposure are in agreement with the previously mentioned results reported by Thurston and Knowles [4], as degradation progressed the proportions of $\mathrm{CO}_{2}$ and water formed became significantly larger.

In both asphalts the nitrogen content increased slightly and then leveled off as degradation progressed as seen in figures 7 and 8 . The nitrogen increase may have come from the oxides of nitrogen in the atmosphere reacting with the unsaturated portions of the asphalt [18]. However, the effect is small and of about the same order of magnitude as the errors involved in the nitrogen determination. The relative constancy of the total nitrogen in both asphalts after the early periods of exposure serves to confirm the validity of the assumptions used in making these calculations.

\subsection{Outdoor Exposures}

The results of the first 18 months of exposure to the weather are reported in tables 6 and 7 . The data ${ }^{5}$ are incomplete, primarily in molecular-weight

\footnotetext{
${ }^{5}$ These results are based on the analyses of individual specimens.
} 


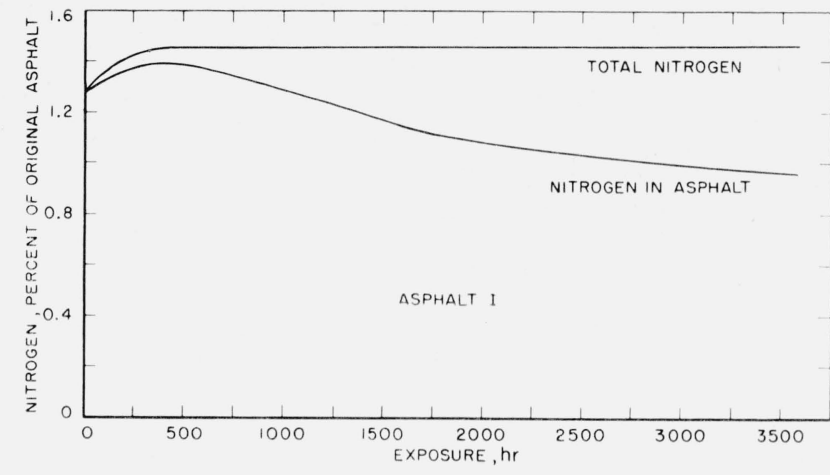

Figure 7. Nitrogen distribution in asphalt I during exposure to accelerated weathering.

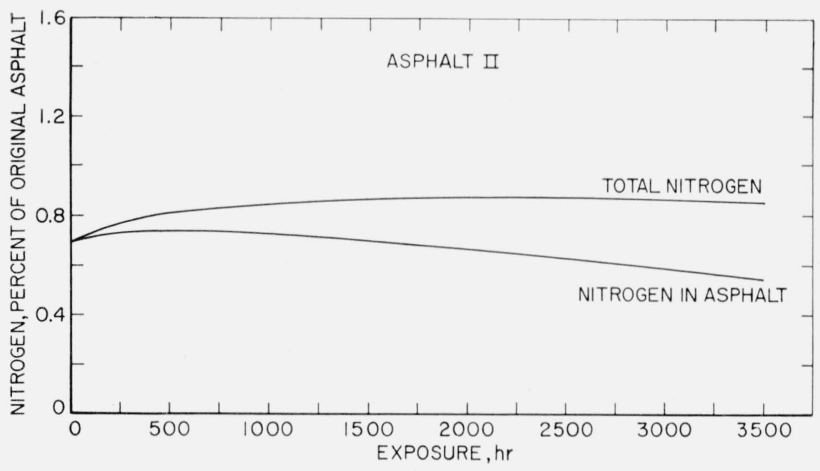

FIgURE 8. Nitrogen distribution in asphalt II during exposure to accelerated weathering.

and nitrogen measurements, and show less tendency toward specific trends than the more closely controlled laboratory exposures. However, there seemed to be a tendency for the molecular weights of the components of asphalt I to decrease. In asphalt II, the average molecular weight of asphaltenes decreased and that of the white oils increased (as in the laboratory exposures). Except for the resins in asphalt I, the carbon-hydrogen ratios of all of the components remained fairly constant. All of the components increased in oxygen content. No definite trends were observed in the changes of the sulfur and nitrogen compounds. In general, possibly because only single specimens were involved, the results of the outdoor exposures did not show significant trends.

\section{Summary and Conclusions}

When asphalts are exposed to light, heat, and water, numerous and complex chemical changes take place. Oxidation occurs and results in the formation of volatile and water-soluble degradation products, which are removed from the asphalt. More than one-third of these weight losses occur from the formation of $\mathrm{CO}_{2}$ and $\mathrm{H}_{2} \mathrm{O}$. About twothirds of the losses go into a water-soluble material that is highly acidic. A fourth product that is insoluble in water and n-pentane remains on the surface of the coatings.

Sulfur and nitrogen are in the molecules that become asphaltenes during the early periods of exposure and are also present in the water-soluble degradation products. The water-soluble degradation products that are formed are almost equal in weight to the measured weight losses. The volatile products represent about two and one-half times the weight losses. A small increase in total nitrogen in the system during the early stages of degradation may indicate reaction of the asphalt with the oxides of nitrogen always present in the atmosphere.

Differences existed between the two coating-grade asphalts studied and in the manner in which they degraded. The principal differences were in the rate of degradation and in the molecular-weight changes. Secondary differences were obvious in the way the sulfur- and nitrogen-containing molecules reacted to form higher molecular-weight components and degradation products.

Although the outdoor exposures were followed for only 18 months, the changes taking place in both asphalts tended to confirm those changes that took place in the accelerated weathering machines.

The help of L. R. Kleinschmidt, S. Ishihara, and $\mathrm{J}$. P. Falzone in collecting the data for this paper is gratefully acknowledged. The author thanks H. R. Snoke, A. Schriesheim, and R. Paulson of NBS for their advice and encouragement.

\section{References}

[1] H. Abraham, Asphalts and allied substances, pp. 14631468 (D. van Nostrand Co., Inc., New York, N.Y., 1954).

[2] L. R. Kleinschmidt and H. R. Snoke, Changes in the properties of an asphalt during the blowing operation, J. Research NBS 60, 169-172 (1958) RP2835.

[3] J. M. Goppel and J. Knotnerus, Fundamentals of bitumen blowing, Proc. Fourth World Petrol. Congr., sec. III/G., 1-13 (1955).

[4] R. R. Thurston and E. C. Knowles, Asphalt and its constituents, oxidation at service temperatures, Ind. Eng. Chem 33, 320 (1941)

[5] H. Abraham, Asphalt and allied substances, pp. 15001508 (D. van Nostrand Co., Inc., New York, N.Y., 1945).

[6] L. R. Kleinschmidt and H. R. Snoke, Effect of light and water on the degradation of asphalt, J. Research NBS 63C, 31-36 (1959).

[7] R. M. Galloway, Chemical composition of asphalt related to road service, Am. Chem. Soc. Symp. Chem. and Composition of Asphalts 3, A53-59 (1958).

[8] S. H. Greenfeld, The effects of mineral additives on the durability of coating-grade roofing asphalts, NBS Building Materials and Structures Report 147, 14 pp. (1956).

[9] S. H. Greenfeld, A method for preparing uniform films of bituminous materials, ASTM Bull. 193, 50-53 (1953)

[10] New laboratory for durability studies of protective coatings, NBS Tech. News Bul. 35, 20-21, 1951. 
[11] L. R. Kleinschmidt, Chromatographic method for the fractionation of asphalt into distinctive groups of components, J. Research NBS 54, 163-166 (1955) RP2577.

[12] S. H. Greenfeld, Characteristics of fifteen coating-grade asphalts, J. Research NBS 64C, 299 (1960).

[13] R. Matteson, Modified molecular weight apparatus, Anal. Chem. 22, 172-175 (1950).

[14] Federal test methods standards 141-Paint, varnish, lacquer and related materials; Methods of inspection, sampling and testing. Method 5061-Iodine number of oils and fatty acids.

[15] K. Van Ness and H. A. Van Westen, Aspects of the constitution of mineral oils (Elsevier Publishing Co., Inc., New York, N.Y., 1951).

[16] F. S. Rostler and R. M. White, Determination of the hydrocarbon type of petroleum products, Rubber Age \%o, 735-747 (1952).
[17] A. Schriesheim and S. H. Greenfeld, The water-soluble degradation products of asphalt, ASTM Bull. No. 220, 43-47 (1957).

[18] J. E. Stewart, Infrared spectra of chromatographically fractionated asphalts, J. Research NBS 58, 265 (1957) RP2759.

[19] B. D. Beitchman, Infrared spectra of asphalts, J. Research NBS 63A, 189 (1959).

[20] P. L. Hanst, E. R. Stephens, and W. E. Scott, Reactions involving ozone, nitrogen dioxide, and organic compounds at low concentrations in air, Proc. Am. Petrol. Inst. 35, III, 175-187 (1955). 